\title{
O Ensino da programação de computadores na perspectiva de Gagné aplicado no contexto da educação prisional
}

\author{
Fábio Ventorim Siqueira - Ifes - fabioguiu2014@gmail.com \\ Márcia Gonçalves de Oliveira - Ifes - clickmarcia@gmail.com
}

\begin{abstract}
Resumo. Robert Mills Gagné foi um psicólogo norte americano muito influente no campo da educação entre as décadas de 60 e 70, onde se destacou ao conseguir harmonizar as principais contribuições behavioristas $e$ cognitivistas em prol da educação. Neste trabalho mostramos que, ao utilizar princípios da teoria da aprendizagem de Gagné, é possivel ensinar programação de computadores a pessoas em privação de liberdade. Nossos resultados demonstram também que é possível manter esses indivíduos ocupados, com o desenvolvimento de soluções computacionais criativas, durante o tempo que antes ficavam ociosos dentro das celas.
\end{abstract}

Palavras-chaves: Programação de Computadores. Educação Prisional. Pensamento Computacional. Ressocialização.

\section{Teaching computer programming from the perspective of Gagné applied in the context of prison education}

\begin{abstract}
Robert Mills Gagné was a very influential North American psychologist in the field of education between the 60s and 70s, where he excelled at being able to harmonize the main behaviorist and cognitive contributions in favor of education. In this work, we show that, using Gagne's theory of learning, it is possible to teach computer programming to people in deprivation of liberty. Our results also demonstrate that it is possible to keep these individuals busy, with the development of creative computational solutions, during the time that they were previously idle inside the cells.
\end{abstract}

Keywords: Computer programming. Education in prison. Computational Thinking. Resocialization.

\section{Introdução}

Cadeias superlotadas com péssimas condições de habitação e higiene. Esse é o retrato que se apresenta atualmente como o mais representativo do sistema prisional brasileiro. Como consequência dessa realidade, o Estado enfrenta grandes dificuldades para promover a ressocialização de pessoas que se encontram em privação de liberdade.

Segundo o último Levantamento Nacional de Informações Penitenciárias (Infopen), divulgado em dezembro de 2017, o sistema prisional brasileiro dispõe de 423.242 vagas, para um contingente de 726.354 internos. São quase dois presos por vaga. Esse alto número de pessoas sob custódia do Estado coloca o país na terceira colocação no ranking dos países com maior número de pessoas presas, perdendo apenas para Estados Unidos e China (BRASIL, 2017). 
Ainda segundo esse relatório, é possível verificar que a população do sistema prisional tem crescido em um ritmo assustador nas duas últimas décadas, já que ela quadruplicou nesse período, passando de pouco mais de 170 mil internos em 1997 para mais de 726 mil em 2017 (BRASIL, 2017). Comparando o crescimento dessa população com o crescimento da população brasileira ${ }^{1}$, chegamos a números alarmantes, que mostram um crescimento dez vezes superior da população prisional.

Essa dificuldade de promover a ressocialização, aliada à superlotação do sistema carcerário, resulta em um cenário aterrorizante que rotineiramente estampa as manchetes de jornais, como as rebeliões de Altamira $^{2}$ e de Manaus $^{3}$ ocorridas em meados de 2019, onde mais de 110 pessoas sob custódia do Estado perderam suas vidas. Apesar de nunca ter sido realizado um estudo no âmbito nacional sobre o tema, existe a percepção generalizada, alimentada muitas vezes por profissionais da segurança pública, de que boa parte da criminalidade praticada no Brasil é originária de criminosos reincidentes e que a taxa de reincidência criminal supera os 70\% (Sapori, 2017).

Tendo como objetivo combater o fenômeno da marginalidade, Saviani (2018) defende que a educação se apresenta como um instrumento capaz de corrigir essas distorções e, por isso, os esforços educativos devem ser intensificados até que esse fenômeno seja superado. Nesse sentido, é importante lembrar que a Lei de Execução Penal $^{4}$ assegura a pessoa presa o direito à assistência educacional, que deve ser oferecido pelo Estado na forma de instrução escolar e formação profissional. Mas, conforme mostrado no Infopen, apenas $11 \%$ da população prisional no Brasil está envolvida em atividades educacionais.

Visando contribuir para que os internos envolvam-se mais em atividades educacionais, desenvolvemos um curso de programação de computadores com base em princípios da teoria da aprendizagem do psicólogo norte americano Robert Mills Gagné. Além de ensinar conceitos essenciais da programação, o curso tem como objetivo desenvolver o pensamento computacional dos alunos com o uso da ferramenta Scratch. Dessa forma, buscamos apresentar também uma nova oportunidade profissional para esses indivíduos, o que poderá contribuir diretamente com o processo de ressocialização deles.

Conforme já destacado por Siqueira e Oliveira (2019), a preocupação em capacitar alunos com perfil tecnológico encontra respaldo nos números apresentados pela Associação Brasileira das Empresas de Tecnologia da Informação e Comunicação (Brasscom $)^{5}$, já que existe uma elevada expectativa de investimento no Brasil, com previsão para criação de 420 mil novos postos de trabalho na área tecnológica. Assim, esse trabalho é uma continuidade da pesquisa realizada por Siqueira e Oliveira (2019), tendo como objetivo a aplicação dessa proposta segundo a perspectiva de Gagné.

Este trabalho está organizado conforme a ordem a seguir. Na Seção 2, destacamos os aportes teóricos, abordando a importância de se pensar estratégias para a educação no cárcere e princípios da teoria de Gagné. Na Seção 3, descrevemos a

\footnotetext{
${ }^{1}$ IBGE. Disponível em: <https://www.ibge.gov.br/>. Acesso: 25 fev. 2020.

${ }^{2}$ Altamira. Disponível em <https://globoplay.globo.com/v/7803351/ > . Acesso: 23 fev. 2020.

${ }^{3}$ Manaus. Disponível em:

$<$ https://brasil.elpais.com/brasil/2019/05/27/politica/1558968277_932277.html>. Acesso: 23 fev. 2020.

${ }^{4}$ LEP. Disponível em: <http://www.planalto.gov.br/ccivil_03/leis/17210.htm>. Acesso 10 mar 2020.

${ }^{5}$ Basscom. Disponível: https://brasscom.org.br/relatorio-setorial-de-tic-2019/. Acesso: 20 fev. 2020.
} 
estratégia desenvolvida. $\mathrm{Na}$ Seção 4, apresentamos os primeiros resultados alcançados com a aplicação da estratégia. Na Seção 5, concluímos com as considerações finais.

\section{Revisão de Literatura}

O pensamento computacional pode ser definido como uma maneira de resolvermos problemas variados de forma eficiente. Essa expressão popularizou-se no meio científico após a publicação do artigo de Jeannette Wing, onde a autora defende que as habilidades que compõem o pensamento computacional sejam trabalhadas em todas as pessoas, sejam elas profissionais envolvidos com computação ou não (Wing, 2006).

Com relação a vida intramuros, estudos apontam que a maioria dos internos prefere o estudo ao trabalho. Os resultados mostram ainda uma redução considerável na probabilidade de reincidência criminal, chegando a 39\% nos casos em que o apenado está envolvido em alguma atividade educacional (Julião, 2010).

No que se refere ao campo da educação, o psicólogo norte americano Robert Mills Gagné foi um nome muito influente nas décadas de 60 e 70 . Ele define a aprendizagem como sendo aquela modificação no comportamento do indivíduo que permanece por um longo período de tempo ou durante toda a sua vida. Dentre suas contribuições deixadas para o campo da educação, podemos destacar o Ato de Aprendizagem e a Hierarquia de Aprendizagem (Gagné, 1980).

\subsection{Ato de Aprendizagem e suas fases}

Segundo Gagné, o processo de aprendizagem na mente do ser humano começa com o armazenamento da informação na memória de curta duração para mais tarde ser transferido para a memória de longa duração. Esse momento de aprendizagem é precedido de alguns eventos e seguido de outros (Gagné, 1980).

Os primeiros eventos estão relacionados à estimulação externa que atua sobre o estudante, ao passo que os últimos eventos correspondem a atividades internas que ocorrem no sistema nervoso central do aprendiz. Essa cadeia de eventos constitui aquilo que Gagné nomeia como Ato de Aprendizagem, sendo composto por oito fases: Motivação, Apreensão, Aquisição, Retenção, Rememoração, Generalização, Desempenho e Feedback (Gagné, 1980).

\subsection{Hierarquia de Aprendizagem}

Gagné também acreditava que toda habilidade cognitiva mais complexa estava ancorada em outras habilidades cognitivas de menor complexidade. Por exemplo, a capacidade para resolver cálculos matemáticos complexos estaria assentada em diversas outras habilidades mais simples, como possuir um raciocínio lógico apurado e dominar operações básicas de soma, subtração, multiplicação e divisão. Assim, segundo ele, só seria possível o desenvolvimento de uma solução de alto nível a partir do domínio das habilidades mais básicas (Gagné, 1980).

Nesse contexto, Gagné sugere que habilidades mais complexas sejam realizadas apenas após o domínio prévio de habilidades mais simples. Essa compreensão de que existe um tipo de hierarquia de habilidades deu origem ao método que ficou conhecido como Hierarquia de Aprendizagem. Na prática, esse método consistia no seguinte: uma vez que o professor estabelecesse o nível de habilidade cognitiva mais alta a ser desenvolvido pelos alunos, ele deveria identificar quais habilidades de baixo nível os 
estudantes já possuíam e quais habilidades de nível intermediário ainda precisavam desenvolver. Uma vez realizado esse diagnóstico, caberia ao professor propor atividades que auxiliassem os alunos a desenvolver essas habilidades intermediárias, que por sua vez serviriam de base para os estudantes alcançarem habilidades de maior complexidade.

\subsection{Trabalhos Relacionados}

A partir desta pesquisa, foi constatada certa carência de trabalhos que se dispõem a estudar o desenvolvimento do pensamento computacional e do ensino de programação em pessoas que se encontram privadas de liberdade. Essa carência se torna ainda mais acentuada ao procurar por trabalhos que possuem como base a teoria da aprendizagem de Gagné.

Porém, é possível encontrar trabalhos semelhantes, como a pesquisa realizada por Pancieri et. al. (2019), que utilizou a robótica educacional para ajudar no processo de recuperação de socioeducandos, trabalhando o pensamento computacional enquanto esses alunos estavam nas celas das unidades de internação. Destacamos também o trabalho de Siqueira e Oliveira (2019), que é uma prévia desta pesquisa que buscou contribuir com o processo de ressocialização de indivíduos privados de liberdade através do desenvolvimento do pensamento computacional utilizando a ferramenta Scratch, mas ainda sem qualquer relato de experiência.

\section{Estratégia Desenvolvida}

Considerando que a pesquisa em questão busca trabalhar com um público específico, com grandes restrições de acesso, foi firmada uma parceria entre a Secretaria de Estado da Justiça do Espírito Santo (Sejus) e o Instituto Federal do Espírito Santo (Ifes) por meio do Centro de Referência em Formação e em Educação a Distância (Cefor). Essa parceria permitiu ao Cefor a criação de um projeto de extensão, em formato de oficinas, para capacitar as pessoas em privação de liberdade. As três oficinas que compõem o curso podem ser vistas a seguir, no Quadro 1.

\section{Quadro 1 - Oficinas aplicadas às pessoas em privação de liberdade}

\begin{tabular}{|c|c|c|}
\hline $\begin{array}{l}1^{\circ} \text { Oficina: } \\
\text { Chute a Gol }\end{array}$ & $\begin{array}{c}2^{\circ} \text { Oficina: } \\
\text { Labirinto de Times }\end{array}$ & $\begin{array}{c}3^{\circ} \text { Oficina: Eleição do }+ \\
\text { Querido do Rio }\end{array}$ \\
\hline $\begin{array}{l}\text { Utilizando a programação em } \\
\text { blocos com a ferramenta Scratch, } \\
\text { nessa oficina os alunos são } \\
\text { orientados a desenvolver pequenas } \\
\text { sequências lógicas para atingir os } \\
\text { objetivos propostos em aula. São } \\
\text { trabalhadas as quatro habilidades } \\
\text { essenciais do pensamento } \\
\text { computacional (Brackmann, 2017), } \\
\text { além de conceitos computacionais } \\
\text { como sequência, evento e } \\
\text { paralelismo. }\end{array}$ & $\begin{array}{l}\text { A proposta desta oficina é que } \\
\text { seja dada continuidade no } \\
\text { desenvolvimento das } \\
\text { habilidades essenciais do } \\
\text { pensamento computacional. } \\
\text { Aqui, também são } \\
\text { apresentados aos estudantes } \\
\text { diversos conceitos } \\
\text { computacionais como } \\
\text { sequência, evento, } \\
\text { paralelismo, loop, } \\
\text { condicionais, operadores e } \\
\text { armazenamento de dados. }\end{array}$ & $\begin{array}{l}\text { Além de dar } \\
\text { continuidade no } \\
\text { desenvolvimento das } \\
\text { principais habilidades do } \\
\text { pensamento } \\
\text { computacional, o foco } \\
\text { desta oficina é fazer com } \\
\text { que os alunos consigam } \\
\text { desenvolver um } \\
\text { programa que contenha } \\
\text { os conceitos de entrada, } \\
\text { processamento e saída de } \\
\text { informação. }\end{array}$ \\
\hline
\end{tabular}

Diante dessa formalização, foi possível garantir ao pesquisador o direito de aplicar as oficinas nas dependências da Penitenciária Semiaberta de Vila Velha (PSVV), 
além de assegurar aos alunos o direito de receberem um certificado emitido pelo Ifes, podendo ser utilizado por eles para remissão de pena.

Os equipamentos utilizados nas oficinas foram: cinco notebooks, usados pelos alunos, além de um notebook e um projetor, utilizados pelo professor. Considerando que a unidade prisional não possuía esses equipamentos, parte foi cedida pela Sejus e parte foi providenciada pelo pesquisador.

\subsection{Planejamento}

Todas as etapas das oficinas foram fundamentadas na teoria de Gagné. Por isso, ao iniciar o planejamento, foi definindo o nível de habilidade cognitiva mais alta a ser desenvolvido nos alunos. E a partir disso, foram montadas oficinas com atividades que proporcionassem aos estudantes alcançar esse patamar de conhecimento. Em seguida, após analisar as fases que compõem o Ato de Aprendizagem, foram elaboradas ações visando atender aquilo que preconiza cada uma das fases. Essas ações podem ser observadas no Quadro 2.

Quadro 2 - Planejamento adotado para as fases do Ato de Aprendizagem

\begin{tabular}{|c|c|}
\hline Fase & Ação Planejada \\
\hline Motivação & $\begin{array}{l}\text { Partindo do princípio de que a motivação é um importante ponto } \\
\text { abordado por Gagné, foi dada ênfase especial a esse critério. Dentre as } \\
\text { ações tomadas, destacam-se as pesquisas realizadas para identificar as } \\
\text { preferências e características do nosso público-alvo. E diante do } \\
\text { depoimento de um interno da Unidade Plácido de Sá Carvalho, que } \\
\text { afirmou: "A grande realidade é que, acho que } 90 \% \text { do coletivo vive em } \\
\text { função do futebol..." (Julião } 2009 \text { p. 232), o futebol foi adotado como } \\
\text { cenário em boa parte das atividades trabalhadas nas oficinas. }\end{array}$ \\
\hline Apreensão & $\begin{array}{l}\text { Considerando que nessa fase o aluno precisa atentar-se para as } \\
\text { informações que lhe são apresentadas, durante as oficinas os alunos são } \\
\text { constantemente alertados para que direcionem sua atenção para o } \\
\text { conteúdo apresentado na aula. Para que esse momento não se torne } \\
\text { maçante, para cada conteúdo repassado, inicialmente os alunos devem } \\
\text { assistir a um vídeo que mostra o produto final (jogo, animação ou } \\
\text { programa) que eles devem desenvolver após receber as devidas } \\
\text { orientações. }\end{array}$ \\
\hline Rememoração & $\begin{array}{l}\text { Essa fase marca o ato de recuperar a informação armazenada na } \\
\text { memória. Por isso, diariamente, os alunos devem ser estimulados, através } \\
\text { de atividades práticas, a recuperar conceitos que foram previamente } \\
\text { ensinados. }\end{array}$ \\
\hline Generalização & $\begin{array}{l}\text { Nessa fase o aluno deve aplicar em um contexto prático aquilo que foi } \\
\text { aprendido em aula. Por isso, além das pequenas atividades realizadas } \\
\text { durante as aulas, os alunos devem receber um desafio ao final de cada } \\
\text { oficina para que assim possam colocar em prática o que foi aprendido } \\
\text { anteriormente. }\end{array}$ \\
\hline Des & $\begin{array}{l}\text { Na fase de desempenho, é possível que o observador avalie se houve } \\
\text { aprendizagem do aluno. Dessa forma, a produção dos alunos será } \\
\text { utilizada para mensurar se houve ou não o aprendizado do estudante. }\end{array}$ \\
\hline
\end{tabular}




Feedback $\left|\begin{array}{l}\text { Considerando que essa fase marca a percepção do aluno frente ao } \\ \text { conhecimento adquirido por ele, foi utilizado o diálogo com os } \\ \text { estudantes, além de um questionário impresso para capturar a percepção } \\ \text { dos aprendizes sobre o conhecimento adquirido. }\end{array}\right|$

\section{Resultados e Discussão}

Os tópicos a seguir abordam os resultados obtidos a partir da aplicação das oficinas na PSVV, que foi realizada de segunda à sexta-feira, durante duas semanas do mês de dezembro de 2019, no horário compreendido entre 08:30 e 11:30. As informações aqui apresentadas são os primeiros resultados do processo de observação do pesquisador, da análise das tarefas realizadas pelos alunos e dos depoimentos desses estudantes.

\subsection{Perfil dos Alunos}

As oficinas foram realizadas com um total de dez alunos. Todos são estudantes da Escola Estadual de Ensino Fundamental e Médio (EEEFM) Cora Coralina, localizada dentro da PSVV. A faixa etária dos alunos variava entre 25 e 45 anos de idade. O grau de escolaridade e o tempo sem manusear computadores também eram bastante diversificados, onde se destaca o fato de que três estudantes nunca haviam tido contato com computadores.
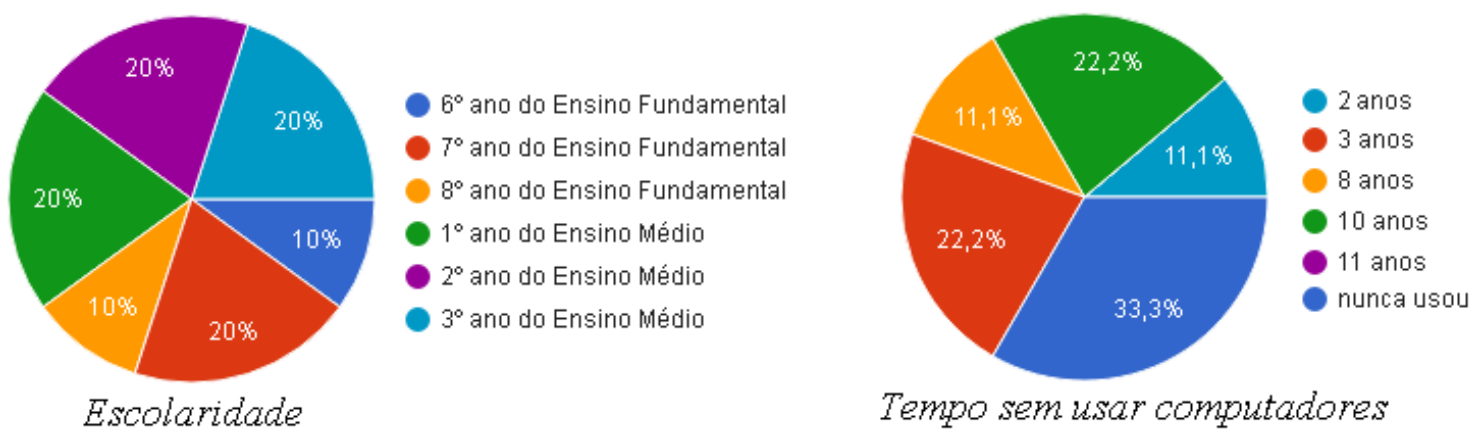

Figura 1 - Escolaridade e tempo sem manuseio de computadores

A tipificação penal não foi considerada como fator de restrição para impedir um interno de participar das oficinas, a exceção dos internos que haviam cometidos crimes sexuais, já que estes ficam separados dos demais presos. Com isso, o tipo de crime cometido por cada aluno, era variado, conforme mostrado no gráfico da Figura 2.

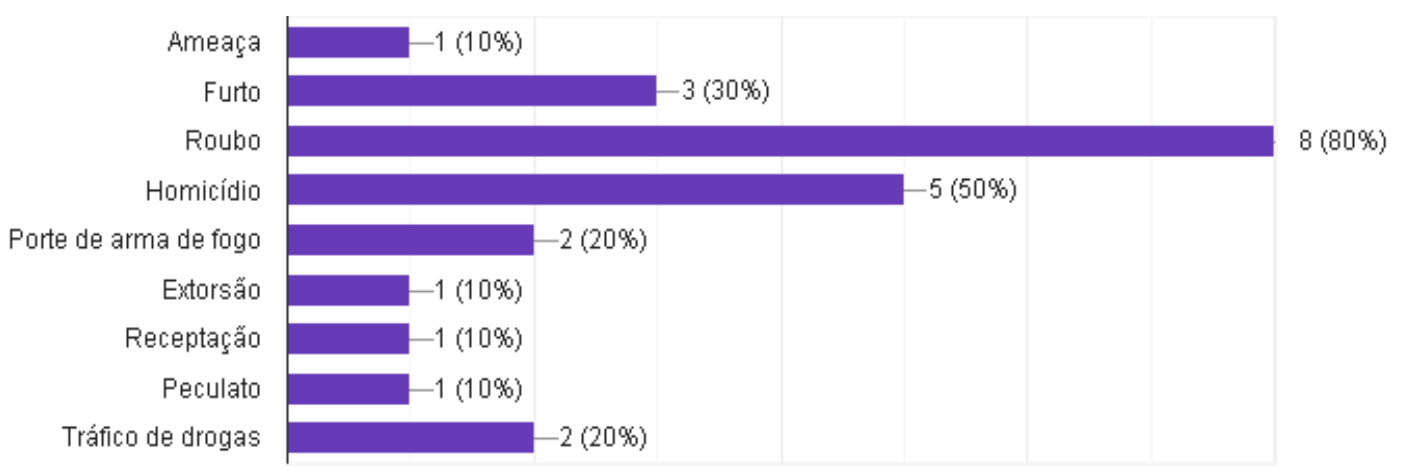

Figura 2 - Distribuição dos crimes consumados pelos alunos

\subsection{Aula Introdutória}

A aula inaugural do curso ocorreu no dia 02/12/2019 e foi marcada pela 
motivação em estudar programação de computadores que foi despertada nos alunos. Além de aprender sobre as quatro habilidades essenciais do pensamento computacional (Brackmann, 2017), os alunos assistiram ao vídeo Todos Devemos Aprender Programação ${ }^{6}$, que foi criado especialmente para essas oficinas. Em seguida, os estudantes conheceram um pouco do projeto The Last $\mathrm{Mil}^{7}$, onde pessoas em privação de liberdade aprendem a programar computadores em prisões da Califórnia - Estados Unidos.

Seguindo com o planejamento traçado para o primeiro dia, foram apresentadas algumas informações do relatório setorial da Brasscom, como comparação entre a média salarial de profissionais que trabalham com tecnologia e demais profissões. Além da grande estimativa para criação de novas vagas de emprego no campo da tecnologia.

\subsection{A realização das oficinas}

Após despertar as expectativas dos alunos em relação às oficinas de programação com a aula introdutória, as atividades práticas no Scratch foram iniciadas. Conforme preconiza a Hierarquia de Aprendizagens, de Robert Gagné, a partir deste momento o objetivo era montar pequenos projetos (jogos, animações, histórias, programas) com os alunos para que eles pudessem conhecer e praticar o uso dos blocos de comandos. Por isso, em cada uma das oficinas, foram trabalhadas diversas atividades que tinham como propósito ensinar conceitos necessários para desenvolver a tarefa final que marcava cada oficina.

Partes dessas atividades eram passadas aos alunos minutos antes do encerramento das aulas e ocorriam da seguinte maneira: A turma assistia a um vídeo (animação, jogo ou programa) que era projetado no quadro. Em seguida, eles deveriam pensar, enquanto estivessem na cela, em como aquele vídeo poderia ser construído utilizando a programação em blocos com a ferramenta Scratch. No dia seguinte, antes de iniciarem a implementação no Scratch, eles precisavam escrever em uma folha de papel os passos, isto é, o que pensaram enquanto estavam nas celas.

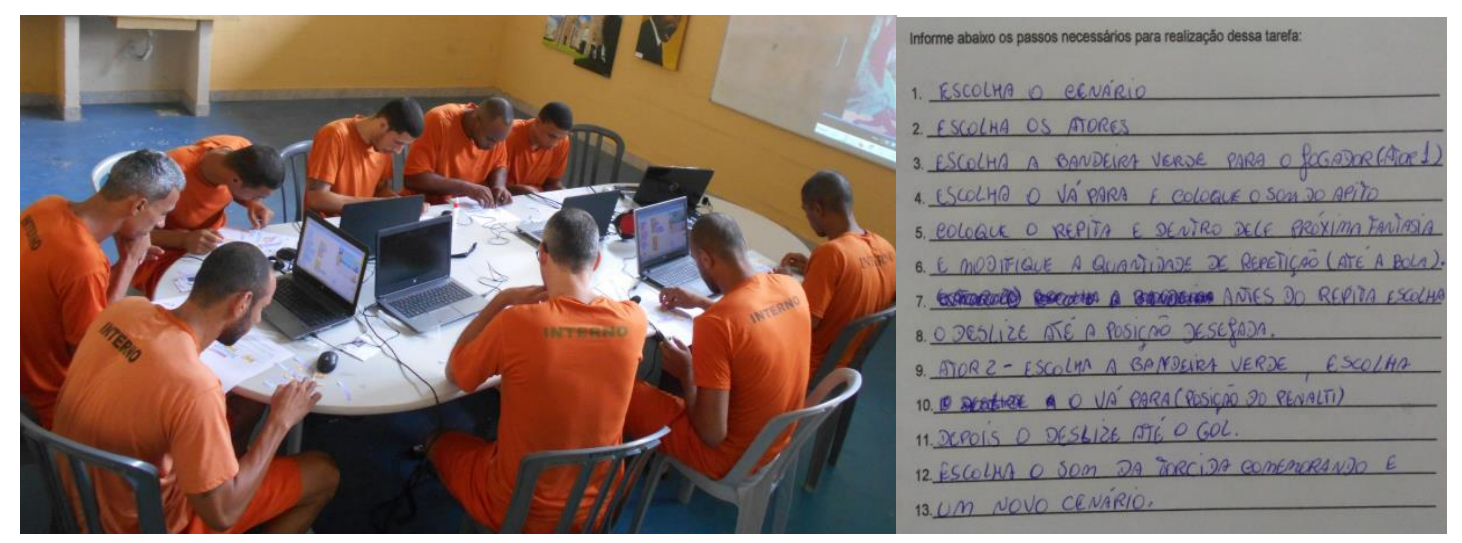

Figura 3 - Alunos realizando tarefas pensadas em cela

Enquanto estavam nas celas, os alunos "literalmente" trabalharam o pensamento computacional. Durante as atividades realizadas nas celas e na sala de aula, de maneira imperceptível, habilidades como abstração, decomposição, reconhecimento de padrão e pensamento algorítmico foram trabalhados com os estudantes.

\footnotetext{
${ }^{6}$ Vídeo incentivando aprender programação. Disponível em: $<$ https://youtu.be/6VeKeJKcnQo $>$

${ }^{7}$ Projeto The Last Mile. Disponível em : <https://thelastmile.org>.
}

V. $18 \mathrm{~N}^{\mathrm{o}} 1$, julho, 2020 RENOTE DOI: 
Durante a realização dessas atividades, os alunos foram estimulados, por exemplo, a pensar e dividir em etapas os procedimentos necessários para montagem de um programa. Outras habilidades essenciais do pensamento computacional também puderam ser trabalhadas nos estudantes, como o reconhecimento de padrões, realizado em diversas atividades onde os alunos foram estimulados a identificar comportamentos que se repetiam para fazerem uso de estruturas de repetição.

O resultado dessa proposta se mostrou muito eficiente para ocupar a mente dos alunos nas celas e pôde ser comprovado através dos depoimentos dos alunos que ocorriam frequentemente como, por exemplo, a resposta de um dos alunos que, quando perguntado se havia pensado em como desenvolver a animação Chute a Gol disse: "Professor... quase perdi os cabelos pensando em como montar essa animação". Ratificando a eficácia dessa proposta foi possível apurar que $88,9 \%$ dos alunos relataram através do preenchimento de questionário que pensaram muitas vezes, em cela, na maneira como poderiam resolver uma tarefa especificada em aula. De acordo com esse questionário, foi possível verificar que todos os alunos souberam descrever ao menos uma tarefa que ocupou sua mente nesse período.

No que se refere ao aprendizado de programação, foi possível verificar um comprometimento e interesse muito grande por parte dos estudantes. Essa motivação provavelmente é resultado da aula inaugural, que apresentou aos alunos os benefícios de se estudar programação, aliada à facilidade de manuseio e ludicidade da ferramenta Scratch.

Com a conclusão da primeira oficina, a maioria dos alunos era capaz de criar animações que envolviam pequenas sequências lógicas. Ao término da segunda oficina, a maior parte dos alunos conseguia desenvolver pequenos jogos e animações que envolviam expressões lógicas, estruturas de repetição e condicionais, que são elementos essenciais para qualquer linguagem de programação.

Após a realização da terceira e última oficina, a maior parte dos alunos era capaz de implementar ações que ocorriam em paralelo, inclusive com o mesmo ator. Dominavam o uso de estrutura de repetição, condicionais e a manipulação de variáveis. Com isso, eram capazes de criar pequenos projetos que envolviam a entrada, o processamento e a saída de informações, como foi o caso da tarefa final que simulou o funcionamento de uma urna eletrônica: Eleição + Querido do Rio ${ }^{8}$.

O bom desempenho dos alunos apurado ao final das oficinas é reflexo da dedicação demonstrada ao longo de todo o curso. Nesse sentido, não há como deixar de mencionar a criatividade e força de vontade demonstradas, em mais de uma oportunidade, por esses estudantes que, mesmo em condições adversas de aprendizagem, como o convívio durante anos em celas muitas vezes superlotadas, com péssimas condições de higiene e habitação, portaram-se de maneira ímpar, demonstrando uma força de vontade que dificilmente é encontrada no ambiente escolar.

Nem mesmo a proibição de portar qualquer tipo de material escolar impediu esses alunos de continuarem os estudos nas celas. Enquanto alguns enxergaram lápis e caderno onde havia apenas pedaços de vassoura piaçava, linhas retiradas do lençol e a tampa do recipiente onde são servidas as refeições, outros alunos improvisavam no

${ }^{8}$ Vídeo do programa Eleição + Querido do Rio. Disponível em <https://youtu.be/FukW1JPQGno> 
próprio corpo o registro de anotações que eram usadas durante o estudo no cárcere. A atitude demonstrada pelos alunos reafirma que a metodologia adotada para o ensino de programação e desenvolvimento do pensamento computacional realmente é uma possibilidade muito eficaz para manter suas mentes ocupadas pensando na solução criativa dos exercícios computacionais vivenciados em sala de aula.

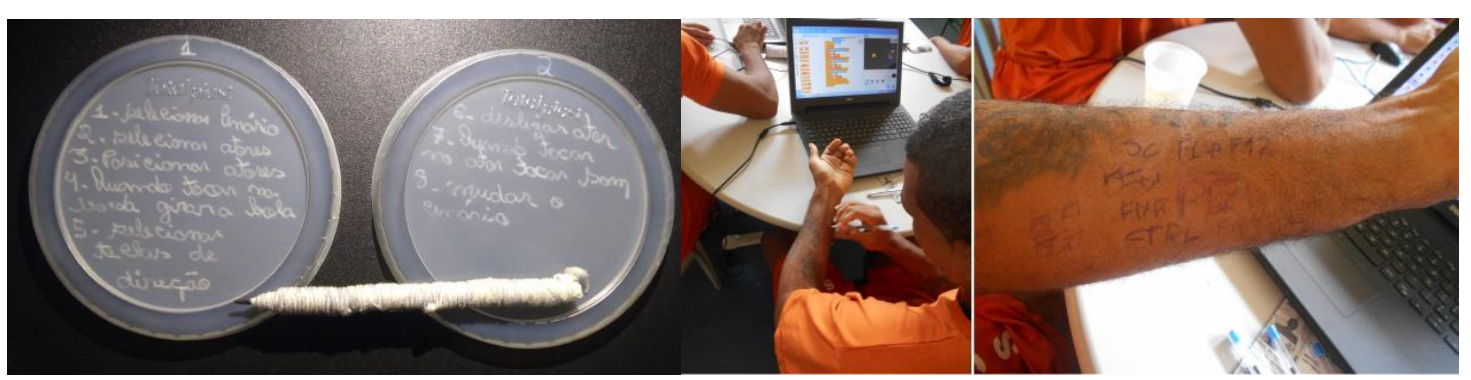

Figura 4 - Exemplo de criatividade e dedicação dos estudantes

\section{Conclusão}

Este trabalho de pesquisa mostrou que é possível obter resultados surpreendentes ao utilizar a teoria de aprendizagem do psicólogo norte-americano Robert Mills Gagné no desenvolvimento do pensamento computacional e no ensino de programação de computadores em blocos para pessoas privadas de liberdade. Para alcançar o objetivo de elaborar um material que fosse baseado na teoria de Gagné, foi utilizada a pesquisa bibliográfica para entender como funciona o processo de aprendizagem na mente do ser aprendiz.

Com base nesse levantamento, as oficinas foram preparadas considerando duas premissas da teoria do psicólogo: as fases do Ato de Aprendizagem e a Hierarquia de Aprendizagem. Dessa forma, foi possível atingir outras duas metas desta pesquisa: ensinar conceitos básicos de programação de computadores aos alunos e manter suas mentes ocupadas na resolução de atividades computacionais mesmo quando esses alunos estavam nas celas.

Trabalhos futuros podem ser realizados de forma a dar continuidade ao trabalho iniciado aqui como, por exemplo, permitir que os alunos possam se aprofundar na aprendizagem de uma linguagem de programação escrita e não apenas de blocos. Trabalhar com banco de dados ou até mesmo com o ensino de informática básica, já que muitos alunos carecem de conhecimentos básicos de informática.

Após a realização deste trabalho, onde foi demonstrado como o ensino de programação de computadores, aliado ao desenvolvimento do pensamento computacional, é um caminho viável para despertar nesses alunos o gosto pelo estudo, esperamos que outros projetos dessa natureza sejam realizados com frequência, dentro ou fora das penitenciárias. Acreditamos que ações dessa natureza, mesmo com um investimento mínimo necessário, poderão contribuir significativamente com o processo de ressocialização desses indivíduos.

Diante dos resultados obtidos na PSVV, esperamos ainda que seja firmada uma nova parceria entre a Sejus e o Ifes de forma a viabilizar que pessoas presas que se encontram no regime semiaberto e que atendam aos requisitos de segurança estipulados pela Sejus possam sair do cárcere para realizar cursos de capacitação nas dependências do Ifes. Acreditamos que a formação de parcerias dessa natureza permitirá a essas pessoas adquirir novas perspectivas de vida, o que certamente contribuirá para a 
diminuição do índice de reincidência criminal.

\section{Referências}

BRACKMANN, Christian Puhlmann. Desenvolvimento do pensamento computacional através de atividades desplugadas na educação básica. Porto Alegre: Universidade Federal do Rio Grande do Sul, 2017. 450p. Tese de Doutorado.

BRASIL. Ministério da Justiça. Departamento Penitenciário Nacional. Levantamento Nacional de Informações Penitenciárias. Brasília, 2017.

GAGNE, Robert M. Princípios essenciais da aprendizagem para o ensino. Editora Globo, 1980.

JULIÃO, Elionaldo Fernandes. Educação para jovens e adultos privados de liberdade: desafios para a política de reinserção social. Salto para o futuro, boletim, v. 6, 2007.

JULIÃO, Elionaldo Fernandes. A ressocialização através do estudo e do trabalho no sistema penitenciário brasileiro. Rio de Janeiro, 2009.

JULIÃO, Elionaldo Fernandes. O impacto da educação e do trabalho como programas de reinserção social na política de execução penal do Rio de Janeiro. Revista Brasileira de Educação, v. 15, n. 45, p. 529-543, 2010.

PANCIERI, Jussara et al. Robotics in the Resocialization of Youngsters and Teenagers in Socio-Educational Measures. In: 2019 Latin American Robotics Symposium (LARS), 2019 Brazilian Symposium on Robotics (SBR) and 2019 Workshop on Robotics in Education (WRE). IEEE, 2019. p. 429-434.

SAPORI, Luis Flávio; SANTOS, Roberta Fernandes; MAAS, Lucas Wan Der. Fatores sociais determinantes da reincidência criminal no Brasil: o caso de Minas Gerais. Revista Brasileira de Ciências Sociais, v. 32, n. 94, 2017.

SAVIANI, Dermeval. Escola e democracia. Autores associados, 2018.

SIQUEIRA, Fabio Ventorim; OLIVEIRA, Márcia Gonçalves. Recompilando o futuro: O pensamento computacional como parte do processo de ressocialização de detentos. In: Anais do IV Congresso sobre Tecnologias na Educação. SBC, 2019. p. 444-453.

WACQUANT, Loïc. As prisões da miséria. Zahar, 2001.

WING, Jeannette M. Computational thinking. Communications of the ACM, v. 49, n. 3, p. 33-35, 2006. 